\title{
Pengaruh Model Pembelajaran Missouri Mathematics Project dengan Metode Talking Stick terhadap Hasil Belajar Siswa MTS Negeri Tuban
}

\author{
Mochamad Akrom $^{1}$, Rita Yuliastuti ${ }^{2}$, Tanti Nawangsari ${ }^{3}$ \\ ${ }^{1}$ Universitas Ronggolawe, Jl. Manunggal 61 Tuban, akromm708@gmail.com \\ ${ }^{2}$ Universitas Ronggolawe, Jl. Manunggal 61 Tuban, riitayuliastuti45@gmail.com \\ ${ }^{3}$ Universitas Ronggolawe, Jl Manunggal 61 Tuban, tantinawangsari@yahoo.com
}

\begin{abstract}
This research aimed to test the influence of the independent variable which is Missouri Mathematics Project (MMP) learning model using talking stick method against its dependent variable which is the outcome of students' mathematics learning, that are conducted on the second semester of 2015/2016 school year. This research used pretest-posttest design and random subject class control. The study population that was used in this research are the whole students of 7th grade of MTS Negeri Tuban that have 9 classrooms which consist of 275 students. The sample on this research is 7th-grade students in class I as experimental class, totaling 31 students that were taught by MMP learning models using talking stick method. While class $\mathrm{H}$ which consist of 29 students is as control class that were taught by direct instruction. The outcome of this research is some effect have shown on the students that are taught by using MMP learning models using talking stick method towards their mathematics learning outcome.

Key word: Missouri Mathematics Project, talking stick method, learning outcomes of mathematics.
\end{abstract}

\begin{abstract}
ABSTRAK
Penelitian ini bertujuan untuk menguji pengaruh variabel bebas model pembelajaran Missouri Mathematics Project (MMP) dengan metode talking stick terhadap variabel terikat hasil belajar matematika siswa, yang dilakukan pada semester genap tahun ajaran 2015/2016. Penelitian ini menggunakan desain pretest-posttest kelas kontrol subjek random. Populasi penelitian ini adalah seluruh siswa kelas VII MTs Negeri Tuban yang berjumlah 9 kelas dengan jumlah siswa 275 orang. Sampel penelitian ini adalah siswa kelas VII I sebagai kelas eksperimen, berjumlah 31 orang yang diberikan pembelajaran dengan model pembelajaran MMP dengan metode talking stick, dan siswa kelas VII H sebagai kelas kontrol, berjumlah 29 orang yang diajar dengan pembelajaran langsung. Hasil penelitian menunjukkan ada pengaruh model pembelajaran MMP dengan metode talking stick terhadap hasil belajaran matematika siswa MTs Negeri Tuban.
\end{abstract}

Kata kunci: Missouri Mathematics Project, metode talking stick, hasil belajar matematika. 


\section{Pendahuluan}

Penyelenggaraan sistem pendidikan di Indonesia pada umumnya belum mengakomodasi kebutuhan peserta didik secara individu karena lebih mengarah pada model pembelajaran yang berorientasi pada kuantitas agar mampu melayani sebanyakbanyaknya peserta didik, dilakukan secara massal dan klasikal [1]. Kegagalan siswa dalam mencapai tujuan pendidikan pada umumnya dipengaruhi oleh faktor intern, yaitu faktor yang berasal dari dalam diri siswa, dan faktor ekstern, yaitu faktor yang berasal dari luar diri siswa, misalnya: keluarga, lingkungan belajar, pola interaksi guru, metode pembelajaran guru dan sebagainya [2].

Berdasarkan observasi yang peneliti lakukan di MTs Negeri Tuban, model pembelajaran yang diterapkan dalam proses pembelajaran sehari-hari adalah model pembelajaran langsung, jadi dapat dikatakan bahwa pembelajaran konvensional di MTs Negeri Tuban ini adalah pembelajaran langsung. Pembelajaran langsung adalah suatu model pembelajaran yang didesain untuk mendukung proses belajar siswa berkaitan dengan pengetahuan deklaratif dan pengetahuan prosedural yang terstruktur dengan baik dengan menerapkan pola kegiatan bertahap [1]. Pembelajaran ini cenderung monoton karena selalu dimulai dengan guru memberikan materi terlebih dahulu di depan kelas dan dilanjutkan dengan beberapa latihan soal. Untuk soal yang serupa dengan contoh yang diberikan oleh guru, tampak sebagian besar siswa mampu menyelesaikannya dengan melihat cara-cara yang ada di papan tulis. Tetapi ketika soal yang diberikan sedikit berbeda dengan contoh, siswa kesulitan dalam menyelesaikannya. Selain itu, konsep diberikan dalam bentuk jadi, serta pembelajaran ditekankan pada drilling untuk mengejar perolehan nilai ujian.

Hasil wawancara lebih lanjut dengan guru matematika dan sebagian siswa memberikan kesimpulan bahwa akar permasalahan adalah pada faktor proses belajar mengajar, yaitu: 1) minimnya aktivitas siswa dalam proses belajar mengajar, didominasi oleh aktivitas mendengar, mencatat penjelasan guru dan latihan soal yang diberikan oleh guru, 2) kurangnya pemberian motivasi pada siswa untuk ikut aktif dalam pembelajaran, sehingga banyak siswa yang kurang peduli, acuh, kurang percaya diri, dan kurang bersemangat dalam belajar, 3) Hasil belajar siswa dalam mata pelajaran matematika kurang memuaskan. Jika masalah tersebut tidak segera diatasi dampak negatifnya adalah siswa terus-menerus berpandangan bahwa matematika merupakan pelajaran yang sulit, tidak menyenangkan dan cenderung membosankan. Akibatnya, hasil belajar matematika siswa tidak maksimal.

Salah satu model pembelajaran yang cocok digunakan dalam pembelajaran matematika yaitu model pembelajaran Missouri Mathematics Project (MMP). Model pembelajaran MMP merupakan suatu program yang didesain untuk menunjang efektivitas penggunaan latihan-latihan agar siswa mencapai peningkatan yang luar biasa[3]. Menurut Krismanto[4], model pembelajaran MMP terdapat lima langkah pembelajaran yaitu:

1. Review (Pengulasan Kembali)

Dalam kegiatan ini, guru dan siswa meninjau ulang apa yang telah dipelajari pada pelajaran yang lalu. Kegiatan peninjauan dapat berupa pemberian pekerjaan rumah (PR), mencongak, atau membuat prakiraan.

2. Pengembangan

Dalam kegiatan pengembangan, guru menyajikan ide baru dan perluasan konsep matematika terdahulu. Siswa diberi tahu tujuan pembelajaran sehingga memiliki antisipasi tentang sasaran pelajaran. Pengembangan akan lebih bijaksana bila 
dikombinasikan dengan kontrol latihan untuk meyakinkan bahwa siswa mengikuti penyajian materi baru itu.

3. Latihan terkontrol

Siswa diminta untuk memberikan respon terhadap serangkaian soal dengan pengawasan dan bimbingan guru untuk menghindari terjadinya miskonsepsi. Pada latihan terkontrol ini respon siswa sangat penting bagi guru dan siswa. Guru harus menginformasikan pada siswa rincian khusus tanggung jawab kelompok dan reward individual berdasarkan pencapaian materi yang dipelajari.

4. Seat work/ kerja mandiri

Dalam kegiatan ini siswa memberikan respon pada soal yang diberikan oleh guru untuk latihan/ perluasan konsep secara mandiri.

5. Penugasan/PR

Pada langkah ini guru dapat memberikan penugasan atau PR kepada siswa mengenai materi yang telah dipelajari.

Selain itu, diperlukan juga suasana pembelajaran yang nyaman dan menyenangkan serta tidak membuat siswa merasa tertekan ketika melaksanakan proses pembelajaran. Hal ini bertujuan agar siswa dapat lebih mudah untuk membuat koneksi antara materi pelajaran yang telah dipelajari dengan materi, informasi atau ide baru, serta memiliki pengalaman belajar yang menyenangkan dan tidak menekan. Dalam kegiatan inilah diperlukan suatu metode yang mampu membuat siswa merasa nyaman, senang dan tidak tertekan ketika proses pembelajaran berlangsung. Metode yang dimaksud adalah metode talking stick. Sama dengan namanya, metode ini biasanya dilakukan dengan bantuan sebuah tongkat. Metode ini telah lama dipakai di Amerika sebagai alat untuk menyampaikan pendapatnya [1]. Dalam pelaksanaannya, metode ini dirasa sangat menarik dan menyenangkan karena kita diwajibkan menyampaikan pendapat kita atau mengutarakan jawaban kita jika mendapatkan tongkat tersebut. Metode ini bermanfaat karena mampu menguji kesiapan siswa, melatih keterampilan siswa dalam membaca dan memahami materi pelajaran dengan cepat, dan mengajak siswa untuk terus siap dalam situasi apapun [5].

Berdasarkan uraian dan penjelasan yang sudah dipaparkan diatas serta berdasarkan hasil observasi dan wawancara yang dilaksanakan di MTs Negeri Tuban, maka didapatkan rumusan masalah dalam penelitian ini yaitu "Adakah pengaruh model pembelajaran Missouri Mathematics Project dengan metode Talking Stick terhadap hasil belajar matematika siswa MTs?”.

\section{Metode Penelitian}

\subsection{Rancangan Penelitian}

Penelitian ini bertujuan untuk menguji ada tidaknya pengaruh model pembelajaran Missouri Mathematics Project dengan metode Talking Stick terhadap hasil belajar siswa MTs. Penelitian ini merupakan penelitian eksperimen dengan pendekatan kuantitatif. Rancangan penelitian yang digunakan dalam penelitian ini adalah desain pretest - posttest kelas kontrol subjek random [6]. Adapun mengenai rancangan dijelaskan dalam Tabel 1.

Populasi penelitian ini adalah seluruh siswa kelas VII MTs Negeri Tuban yang berjumlah 9 kelas dengan jumlah siswa 275 orang. Sampel penelitian adalah kelas VII-I sebagai kelas eksperimen dan VII-H sebagai kelas kontrol.

TABEL 1 Desain Pretest/Posttest Kelas Kontrol Subjek Random 


\begin{tabular}{ccccc}
\hline & Kelas & Pretest & Perlakuan & Posttest \\
\hline$(\mathrm{R})$ & Eksperimen & $O_{1}$ & $\mathrm{X}$ & $O_{2}$ \\
$(\mathrm{R})$ & Kontrol & $O_{1}$ & - & $O_{2}$ \\
\hline
\end{tabular}

Keterangan :

(R) : Subjek dipilih secara random (acak)

$\mathrm{X}$ : Perlakuan pembelajaran matematika menggunakan model pembelajaran Missouri mathematics project dengan talking stick

- $\quad$ : Perlakuan pembelajaran sesuai dengan yang biasa dilakukan di kelas yaitu pembelajaran langsung.

$O_{1} \quad$ : Pretest yang diberikan pada kedua kelas untuk melihat kemampuan awal siswa sebelum perlakuan.

$\mathrm{O}_{2}$ : Posttest yang diberikan pada kedua kelas untuk melihat kemampuan siswa setelah adanya perlakuan.

\subsection{Jenis Data}

Jenis data dalam penelitian ini adalah data kuantitatif, yaitu berupa skor nilai tes hasil belajar matematika dan menggunakan sumber data primer yaitu suatu data yang diperoleh dari sumbernya langsung. Instrumen tes yang digunakan dalam penelitian ini adalah test hasil belajar matematika.

\subsection{Teknik Pengumpulan Data}

Teknik pengumpulan data yang digunakan dalam penelitian ini adalah tes yang terdiri dari tes awal (pretest) dan tes akhir (posttest). Tujuan pemberian tes awal (pretest) adalah untuk mengetahui kemampuan awal matematika siswa, sementara tujuan pemberian tes akhir (posttest) adalah untuk mengetahui hasil belajar matematika siswa.

\subsection{Teknik Analisis Data}

Dalam penelitian ini, terdapat dua tahap dalam analisis data yaitu analisis awal dan analisis akhir. Analisis awal menggunakan data pretest bertujuan untuk menguji bahwa siswa dalam kelas control dan kelas eksperimen memiliki kemampuan matematika yang sama di awal penelitian. Analisis akhir menggunakan data nilai posttest bertujuan untuk mengetahui ada tidaknya perbedaan hasil belajar siswa antara yang mendapat perlakuan, yakni siswa yang diajar menggunakan model pembelajaran Missouri Mathematics Project dengan metode Talking Stick dengan siswa yang diajar menggunakan model pembelajaran yang biasa diberikan yaitu pembelajaran langsung.

Untuk mengetahui kedua hal tersebut, teknik analisis data yang digunakan baik data nilai pretest maupun data nilai posttest menggunakan uji-t untuk dua sampel bebas setelah dilakukan uji prasyarat yaitu uji normalitas dan homogenitas varians.

\section{Hasil Penelitian dan Pembahasan}

\subsection{Hasil Penelitian}

Berdasarkan hasil analisis maka diperoleh informasi sebagai berikut.

\subsubsection{Analisis Data Kemampuan Awal (Pretest)}


Analisis data kemampuan awal bertujuan untuk mengetahui adanya kesamaan kemampuan awal pada kelas eksperimen dan kelas kontrol sebelum penelitian. Sebelum di analisis uji-t untuk dua sampel maka dilakukan uji prasyarat yaitu uji normalitas dan uji homogenitas varians. Dari uji normalitas, diperoleh hasil sebagai berikut:

TABEL 1 Hasil Uji Normalitas Data Pretest

\begin{tabular}{llrrrrrrr}
\hline & & \multicolumn{3}{c}{ Kolmogorov-Smirnov } & \multicolumn{3}{c}{ Shapiro-Wilk } \\
& Kelas & Statistic & df & Sig. & Statistic & Df & Sig. \\
\hline hasil belajar & kelas &, 124 & 31 &, $121^{*}$ &, 978 & 31 &, 758 \\
matematika & $\begin{array}{l}\text { eksperimen } \\
\text { kelas control }\end{array}$ &, 105 & 29 &, $200^{*}$ &, 952 & 29 &, 201 \\
\hline
\end{tabular}

a. Lilliefors Significance Correction

*. This is a lower bound of the true significance.

Hipotesis yang dirumuskan adalah sebagai berikut.

$\mathrm{H}_{0}$ : sampel berasal dari populasi yang berdistribusi normal

$\mathrm{H}_{1}$ : sampel berasal dari populasi yang tidak berdistribusi normal

Adapun kriteria pengambilan keputusan jika Sig. $>0,05$ maka terima $\mathrm{H}_{0}$, jika sebaliknya Sig $<0,05$ maka tolak $\mathrm{H}_{0}$. Dari Tabel 1 diperoleh informasi bahwa Sig. data pretest kelas eksperimen dalam uji Kolmogorov-Smirnov adalah 0,200 dan uji ShapiroWilk adalah 0,758. Sedangkan Sig. data pretest kelas kontrol dalam uji kolmogorovsmirnov adalah 0,121 dan uji Shapiro-Wilk adalah 0,201. Berdasarkan kriteria yang dipakai nilai Sig. untuk kedua data baik menggunakan uji Kolmogorov-Smirnov maupun uji Shapiro-Wilk, lebih besar dari 0,05 maka $\mathrm{H}_{0}$ diterima. Jadi dapat disimpulkan kedua data pretest berdistribusi normal. Sedangkan dari uji homogenitas varians dapat diperoleh informasi sebagai berikut:

TABEL 2 Hasil Uji Homogenitas Varians Data Pretest

\begin{tabular}{llrrrr}
\hline & & Levene & & & \\
& & Statistic & df1 & df2 & \multicolumn{1}{c}{ Sig. } \\
\hline hasil belajar & Based on Mean &, 311 & 1 & 58 &, 579 \\
matematika & Based on Median &, 204 & 1 & 58 &, 654 \\
& Based on Median and &, 204 & 1 & 57,975 &, 654 \\
& with adjusted df & & & & \\
& Based on trimmed mean &, 296 & 1 & 58 &, 588 \\
\hline
\end{tabular}

Hipotesis yang digunakan adalah.

$\mathrm{H}_{0}$ : Tidak ada perbedaan varians yang signifikan antara nilai pretest kelas eksperimen dan kelas kontrol.

$\mathrm{H}_{1}$ : Ada perbedaan varians yang signifikan antara nilai pretest kelas eksperimen dan kelas kontrol.

Dari Tabel 2 diperoleh nilai probabilitas atau Sig. adalah 0,579. Berdasarkan kriteria yang digunakan maka $0,579>0,05$. Jadi keputusannya terima $\mathrm{H}_{0}$, artinya tidak ada perbedaan varians antara nilai pretest kelas eksperimen dan kelas kontrol. 
Berdasarkan hasil perhitungan program IBM SPSS Statistic 19 diperoleh hasil uji t untuk dua sampel bebas pada Tabel 3 .

TABEL 3 Hasil Uji-t untuk Dua Sampel Bebas Data Pretest

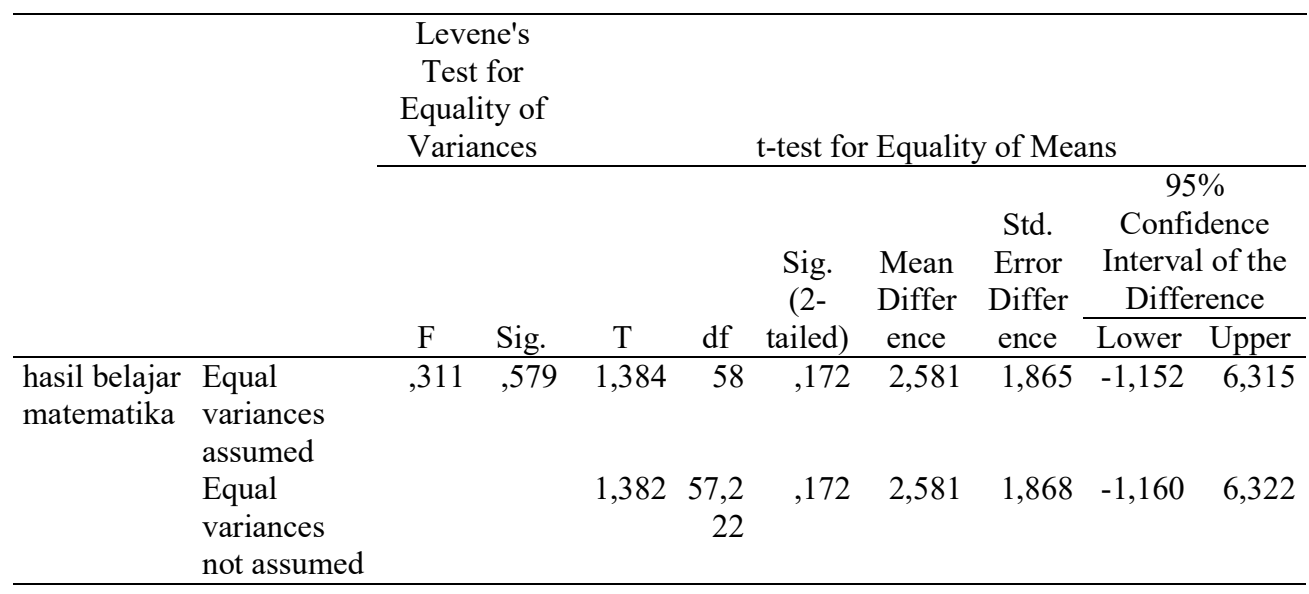

Hipotesis yang digunakan adalah:

$\mathrm{H}_{0}$ : Tidak ada perbedaan yang sinifikan hasil belajar matematika antara kelas eksperimen dan kelas kontrol

$\mathrm{H}_{1}$ : Ada perbedaan yang sinifikan hasil belajar matematika antara kelas eksperimen dan kelas kontrol

Kriteria pengambilan keputusan adalah jika $t_{n_{1}+n_{2}-2}^{\frac{a}{2}}<t_{\text {hitung }}<t_{n_{1}+n_{2}-2}^{\frac{a}{2}}$ keputusannya terima $\mathrm{H}_{0}$, sebaliknya jika $t_{\text {hitung }} \leq t_{n_{1}+n_{2}-2}^{\frac{a}{2}}$ atau $t_{\text {hitung }} \geq t_{n_{1}+n_{2}-2}^{\frac{a}{2}}$, maka tolak $\mathrm{H}_{0}$. Berdasarkan Tabel 2 dapat diperoleh $t_{\text {hitu }} \bar{g}=1,384$ dan nilai sig. $=0,579$. Sedangkan $t_{\text {tabel }}$ untuk $\frac{\alpha}{2}=0,025$ dan derajat bebas 58 adalah 2,002. Karena -2,002< $1,384<2,002$ maka keputusannya $\mathrm{H}_{0}$ diterima. Sehingga dapat disimpulkan bahwa tidak ada perbedaan rata-rata hasil belajar matematika antara kelas eksperimen dan kelas kontrol. Jadi antara kelas eksperimen dan kelas kontrol mempunyai kemampuan awal yang sama.

\subsubsection{Analisis Akhir Data Posttest}

Analsis akhir data postest dilakukan terhadap hasil belajar matematika setelah mengikuti pembelajaran dengan model pembelajaran MMP dengan metode Talking Stick pada kelas eksperimen dan pembelajaran biasa diberikan yaitu pembelajaran langsung pada kelas kontrol. Pengujian ini dilakukan untuk membuktikan kebenaran hipotesis yang diajukan.

Pengujian hipotesis dilakukan dengan menganalisis data tes hasil belajar mata pelajaran matematika mennggunakan data postest. Pengujian hipotesis tersebut dilakukan dengan menggunakan uji-t untuk dua sampel bebas.

Sebelum dilakukan uji-t untuk dua sampel bebas, dilakukan uji normalitas dan uji homogenitas varians. Dari uji normalitas diperoleh informasi sebagai berikut: 
TABEL 4 Hasil Uji Normalitas Data Postest

\begin{tabular}{lllllllll}
\hline & & \multicolumn{3}{c}{ Kolmogorov-Smirnov } & \multicolumn{4}{c}{ Shapiro-Wilk } \\
\cline { 2 - 8 } & Kelas & Statistic & Df & Sig. & Statistic & Df & Sig. \\
\hline $\begin{array}{l}\text { hasil belajar } \\
\text { matematika }\end{array}$ & $\begin{array}{l}\text { kelas } \\
\text { eksperimen }\end{array}$ &, 109 & 31 &, $200^{*}$ &, 952 & 31 &, 173 \\
& kelas control &, 081 & 29 &, $200^{*}$ &, 979 & 29 &, 812 \\
\hline
\end{tabular}

a. Lilliefors Significance Correction

*. This is a lower bound of the true significance.

Hipotesis yang digunakan adalah sebagai berikut.

$\mathrm{H}_{0}$ : Sampel berasal dari populasi yang berdistribusi normal

$\mathrm{H}_{1}$ : Sampel berasal dari populasi yang tidak berdistribusi normal

Taraf kepercayaan yang digunakan adalah 95\%, sehingga dalam pengujiannya kriteria yang digunakan adalah jika probabilitas atau Sig. $>0,05$ maka $\mathrm{H}_{0}$ diterima, sebaliknya jika Sig. $<0,05$ maka $\mathrm{H}_{0}$ ditolak. Dari tabel program IBM SPSS 19.0 for windows di atas diperoleh Sig. pada kelas eksperimen dalam uji Kolmogorov-Smirnov adalah 0,200 dan uji Shapiro-Wilk adalah 0,173. Berdasarkan kriteria yang dipakai, maka 0,200 >0,05 dan $0,173>0.05$. Pada kelas kontrol dalam uji Kolmogorov-Smirnov adalah 0,200 dan uji Shapiro-Wilk adalah 0,812. Berdasarkan kriteria yang dipakai, maka 0,200>0,05 dan $0,812>0.05$. Jadi keputusannya adalah $\mathrm{H}_{0}$ diterima baik menggunakan uji KolmogorovSmirnov maupun uji Shapiro-Wilk, artinya kedua data posttest berdistribusi normal. Sedangkan dari uji homogenitas varians diperoleh informasi sebagai berikut:

TABEL 5 Hasil Uji Homogenitas Varians Data Posttest

\begin{tabular}{|c|c|c|c|c|c|}
\hline & \multicolumn{5}{|c|}{ Levene } \\
\hline & & Statistic & df1 & $\mathrm{df} 2$ & Sig. \\
\hline hasil belajar & Based on Mean & 1,161 & 1 & 58 & ,286 \\
\hline \multirow[t]{3}{*}{ matematika } & Based on Median & 1,028 & 1 & 58 &, 315 \\
\hline & $\begin{array}{l}\text { Based on Median and } \\
\text { with adjusted df }\end{array}$ & 1,028 & 1 & 57,101 &, 315 \\
\hline & Based on trimmed mean & 1,195 & 1 & 58 & 279 \\
\hline
\end{tabular}

Hipotesis yang digunakan adalah:

$\mathrm{H}_{0}$ : Tidak ada perbedaan varians antara nilai posttest kelas eksperimen dan kelas kontrol $\mathrm{H}_{1}$ : Ada perbedaan varians antara nilai posttest kelas eksperimen dan kelas kontrol

Dari Tabel 5 diperoleh nilai probabilitas atau Sig. adalah 0,286. Berdasarkan kriteria yang digunakan maka $0,286>0,05$. Jadi keputusannya terima $\mathrm{H}_{0}$, artinya tidak ada perbedaan varians antara nilai posttest kelas eksperimen dan kelas kontrol.

Selanjutnya dilakukan uji-t untuk dua sampel bebas. Hasil uji-t untuk dua sampel bebas pada data posttest dapat dilihat pada Tabel 6 . 
Pengaruh Model Pembelajaran Missouri Mathematics Project dengan Metode Talking Stick Terhadap Hasil Belajar Matematika Siswa Mts Negeri Tban

TABEL 6 Hasil Uji-t untuk Dua Sampel Bebas Data Postest

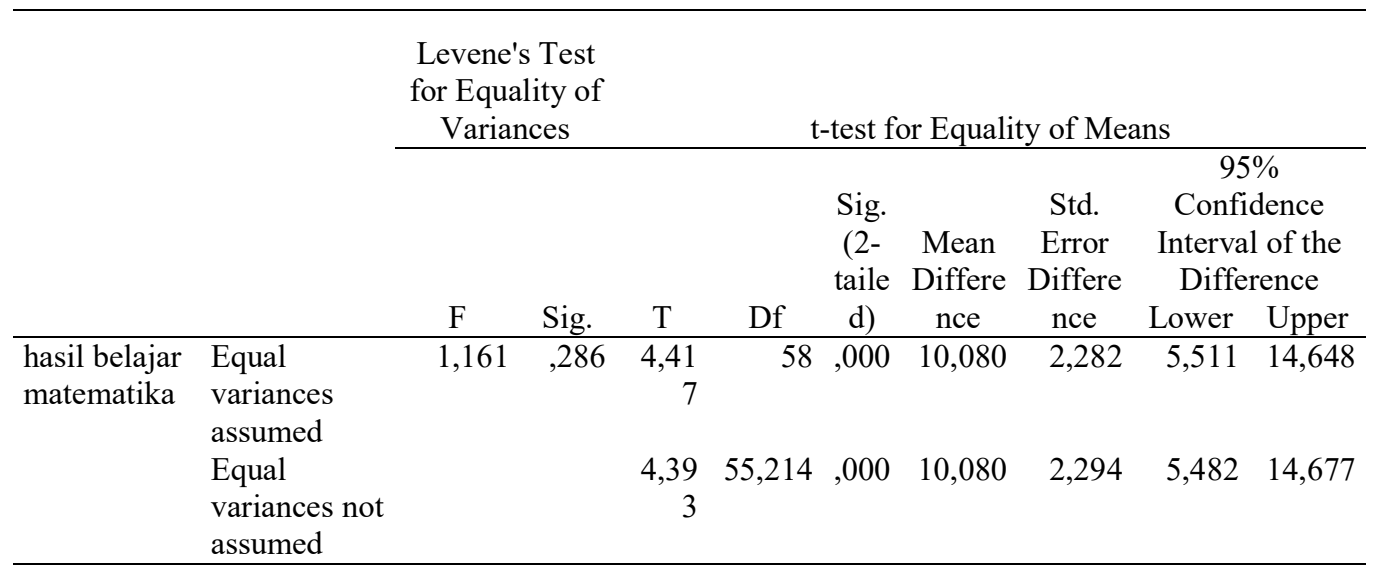

Hipotesis yang diajukan adalah:

$\mathrm{H}_{0}$ : Tidak ada perbedaan yang signifikan hasil belajar matematika siswa yang diberikan model pembelajaran Missouri Mathematics Project dengan metode Talking Stick dan hasil belajar siswa yang diberikan model pembelajaran yang biasa digunakan di kelas yaitu model pembelajaran langsung

$\mathrm{H}_{1}$ : Ada perbedaan yang signifikan hasil belajar matematika siswa yang diberikan model pembelajaran missouri mathematics project dengan metode talking stick dan hasil belajar siswa yang diberikan model pembelajaran yang biasa digunakan di kelas yaitu model pembelajaran langsung

Kriteria pengambilan keputusan adalah jika $t_{n_{1}+n_{2}-2}^{\frac{a}{2}}<t_{\text {hitung }}<t_{n_{1}+n_{2}-2}^{\frac{a}{2}}$ keputusannya adalah menerima $\mathrm{H}_{0}$, sebaliknya jika $t_{\text {hitung }} \leq t_{n_{1}+n_{2}-2}^{\frac{a}{2}}$ atau $t_{\text {hitung }} \geq$ $t_{n_{1}+n_{2}-2}^{\frac{a}{2}}$ maka $\mathrm{H}_{0}$ ditolak. Dari Tabel 6 diperoleh $t_{\text {hitu } n g}=4,417$ dan nilai sig. $=0,000$. sedangkan $t_{\text {tabel }}$ untuk $\frac{\alpha}{2}=0,025$ dan derajat bebas 58 adalah 2,002. Karena 4,417>2,002, maka keputusannya $\mathrm{H}_{0}$ ditolak. Sehingga dapat disimpulkan bahwa ada perbedaan yang signifikan hasil belajar matematika siswa antara kelas yang diberikan model pembelajaran Missouri Mathematics Project dengan metode Talking Stick dan kelas yang diberikan model pembelajaran yang biasa digunakan di kelas yaitu model pembelajaran langsung pada pokok bahasan Transformasi kelas VII MTs Negeri Tuban tahun pelajaran 2015/2016.

\subsection{Pembahasan}

Hasil analisis uji hipotesis menunjukkan bahwa data hasil belajar matematika (posttest) kelas eksperimen dan kelas kontrol berdistribusi normal dengan nilai sig. $>0,05$. Pada uji- $t$ untuk dua sampel bebas pada skor posttest diketahui $t_{\text {hitu }}$ g $=4,417$ dan nilai sig. $=0,00$. Sedangkan $t_{\text {tabel }}$ untuk $\alpha / 2=0,025$ dan derajat bebas 58 adalah 2,002. Karena $t_{\text {hitu } n g} \geq t_{\left(n_{1}+n_{2}-2\right)}^{a / 2}$, yaitu $4,417 \geq 2,002$, maka keputusan $\mathrm{H}_{0}$ ditolak. Dapat disimpulkan bahwa ada perbedaan yang signifikan hasil belajar matematika antara kelas eksperimen dan kelas kontrol.

Hasil analisis pada penelitian ini adalah ada perbedaan yang signifikan antara hasil belajar matematika siswa (posttest) yang diberikan model pembelajaran Missouri 
Mathematics Project dengan metode Talking Stick dan hasil belajar matematika siswa yang diberikan model pembelajaran yang biasa digunakan di kelas yaitu model pembelajaran langsung pada pokok bahasan Transformasi kelas VII MTs Negeri Tuban tahun ajaran 2015/2016. Perbedaan tersebut muncul karena adanya perlakuan terhadap kelas eksperimen, yaitu diberikannya pembelajaran matematika dengan model pembelajaran Missouri Mathematics Project dengan metode Talking Stick. Sementara, variabel yang lain seperti guru, fasilitas, materi pelajaran, soal tes hasil belajar dan lainnya relatif sama. Dengan demikian dapat dikatakan ada pengaruh model pembelajaran Missouri Mathematics Project dengan metode Talking Stick terhadap hasil belajar matematika siswa.

Hasil tersebut selaras dengan pernyataan Purwanti yang menyatakan bahwa model pembelajaran Missouri Mathematics Project merupakan suatu program yang didesain untuk membantu guru dalam hal efektivitas penggunaan latihan-latihan agar siswa mencapai peningkatan yang luar biasa [3]. Selain itu, metode Talking Stick memiliki kelebihan yaitu dalam suasana belajar yang terbuka dan demokratis, siswa dapat mengembangkan pengetahuan, kemampuan dan ketrampilan secara penuh untuk meningkatkan kemajuan belajar sehingga memberikan hasil evaluasi yang memuaskan [7]. Bahkan, pembelajaran Missouri Mathematics Project juga memberikan pengaruh terhadap kemampuan berpikir kreatif siswa [8] dan pemecahan masalah siswa [9].

\section{Kesimpulan}

Berdasarkan hasil analisis data penelitian dan pembahasan dapat disimpulkan bahwa ada pengaruh model pembelajaran Missouri Mathematics Project dengan metode Talking Stick terhadap hasil belajar matematika siswa Kelas VII MTs Negeri Tuban pada pokok bahasan Transformasi.

\section{UcapanTerima Kasih}

Kami sampaikan terima kasih kepada Rektor Unirow Tuban beserta sivitas akademika Unirow Tuban yang telah memberikan layanan yang baik dan berbagai fasilitas untuk mendukung penelitian ini, Kepala Lembaga Penelitian yang telah memberikan ijin pengesahan untuk melakukan penelitian, Dekan FKIP, Kaprodi Pendidikan Matematika, Bapak dan Ibu dosen di lingkungan Prodi Pendidikan Matematika yang telah banyak memberikan bimbingan dan masukan sehingga makalah ini terselesaikan dengan baik, Kepala Sekolah, bapak dan ibu guru serta Karyawan di MTs Negeri Tuban yang telah memberikan waktu, kesempatan, ijin dan fasilitas serta layanan yang baik selama kami mengadakan penelitian ini, serta kepada semua pihak yang telah memberikan bantuan baik langsung maupun tidak langsung dalam penulisan makalah ini.

\section{Daftar Pustaka}

[1] A. Shoimin. 68 Model Pembelajaran Inovatif dalam Kurikulum 2013, Yogyakarta: Ar-ruzz Media, 2014.

[2] D. Sugianto, Belajar dan Pembelajaran I. Tuban :Universitas PGRI Ronggolawe Tuban, 2010.

[3] D. Purwanti, "Penerapan Model Pembelajaran MMP (Missouri Mathematics Project) Dengan Metode Talking Stick Pada Pokok Bahasan Dimensi Tiga Pada Siswa Kelas X SMA Negeri 1 Pamotan Tahun Pelajaran 2011/2012," Skripsi Tidak Diterbitkan. Tuban: Fakultas Keguruan dan Ilmu Pendidikan Universitas PGRI Ronggolawe Tuban, 2012. 
Pengaruh Model Pembelajaran Missouri Mathematics Project dengan Metode Talking Stick

Terhadap Hasil Belajar Matematika Siswa Mts Negeri Tban

[4] A. Krismanto, "Beberapa Teknik, Model, dan Strategi dalam Pembelajaran Matematika," Makalah materi Pelatihan Instruktur/Pengembang SMU, 28 Juli s.d. 10 Agustus 2003, Yogyakarta: Departemen Pendidikan Nasional Direktorat Jenderal Pendidikan Dasar dan Menengah. PPPG Matematika Jogyakarta, 2003.

[5] M. Huda, Model-model Pengajaran dan Pembelajaran, Yogyakarta: Pustaka Belajar, 2013.

[6] Z. Arifin, Membangun Kompetensi Pedagogis Guru Matematika, Surabaya: Lentera Cendikia, 2009.

[7] Mudawamah, "Pengaruh Pembelajaran Kooperatif Tipe Classwide Peer Tutoring dengan Metode Talking Stick Terhadap Kemampuan Komunikasi Matematika Siswa," Skripsi Tidak Diterbitkan, Tuban: Fakultas Keguruan dan Ilmu Pendidikan Universitas PGRI Ronggolawe Tuban, 2014.

[8] N. Marliani, "Pengaruh Model Pembelajaran Missouri Mathematics Project Terhadap Kemampuan Berpikir Matematis Siswa," JPPM, vol. 9, no. 1, 2016.

[9] I. Handayani I, R. L. Januar R L dan S.E. Purwanto, "The Effect of Missouri Mathematics Project learning Model on Students' mathematical Problem solving Ability," Journal of Physics Conf. Series 948. 2018 